\title{
The non-linear effect of methane on climate in a three-dimensional Archean atmosphere
}

\author{
JAKE K. EAGER, NATHAN J. MAYNE AND TIMOTHY M. \\ LENTON \\ University of Exeter \\ Presenting Author: jke205@exeter.ac.uk
}

The interaction between reduced gases and the pre-oxygenic photosynthesising microbial population is key to determining the potential methane greenhouse that warmed the Archean. The potential biotic methane flux could have sustained methane concentrations between 100 to $35,000 \mathrm{ppm}$ [1]. Looking at the effect of these methane fluxes and concentrations in a 3D atmosphere are crucial to understanding these processes in more detail.

Here, I will present results from a state-of-the-art 3D climate model [2] along with a low dimensional biogeochemical model [3], exploring the potential biotic methane fluxes and subsequent concentrations. From this, we can examine the potential climate conditions during the Archean. We have extended a 1D exploration of methane's diminished greenhouse potential during the Archean [4] by looking at how methane concentrations affect cloud distribution, atmospheric dynamics and the surface temperature.

We find that global surface temperature peaks at $\mathrm{pCH}_{4}$ $\sim 1000$ ppmv over a range of $\mathrm{CO}_{2}$ concentrations. Equator-to-pole temperature differences also has a peaked response, with the impact strongly dependant on the $\mathrm{CO}_{2}$ concentration. These changes come about from the balance between the effect of methane and carbon dioxide on atmospheric dynamics. This is due to changes in the heating structure of the atmosphere, which also affects the cloud distribution.

[1] Kharecha, Kasting \& Siefert (2005) Geobiology 3, 53-76.

[2] Mayne et al. (2014) Geosci. Model Dev. 7, 3059-3087.

[3] Lenton \& Daines (2017) Ann. Rev. Mar. Sci. 9:1, 31-58.

[4] Byrne \& Goldblatt (2015) Clim. Past 11, 559-570. 